\title{
INTEGRATED SYSTEM TEST OF AN AIRBREATHING ROCKET (ISTAR)
}

\author{
Robert F. Faulkner \\ $\mathrm{RBC}^{3}$ Chief Engineer
}

\begin{abstract}
Rocket Based Combined Cycle (RBCC) propulsion system development and ground test is being conducted as part of the NASA Marshall Space Flight Center Integrated System Test of an Airbreathing Rocket (ISTAR) program. Rocketdyne, Aerojet and Pratt \& Whitney have teamed as the Rocket Based Combined Cycle Consortium $\left(\mathrm{RBC}^{3}\right)$ to work the propulsion system development. Each company offered unique RBCC propulsion concepts as candidates for the ISTAR propulsion system. A team of engine contractor, vehicle contractor and NASA representatives reviewed the concepts proposed by each company, reviewed the available data and selected the Aerojet RBCC propulsion system concept as the team propulsion system baseline for the ISTAR program. The ISTAR program is currently in a "Jumpstart" phase for development of the engine system leading to ground test of a thermally and power balanced RBCC propulsion system at Stennis Space Center in 2005. A parallel flight test demonstration of this propulsion system is anticipated to lead to first flight in the 2007 timeframe.
\end{abstract}

\section{Introduction}

The Advanced Space Transportation Program at the NASA Marshall Space Flight Center contains four Investment Areas: $2^{\text {nd }}$ Generation RLV, Spaceliner 100, In-Space and Space Transportation Research. Within the Spaceliner 100 Investment Area, NASA Marshall has brought together Government and Industry representatives to conduct a ground test of a Rocket Based Combined Cycle (RBCC) propulsion system. It is envisioned that this hydrocarbon fueled RBCC propulsion system will be used to power a flight test vehicle from launch off a B-52 aircraft up to scramjet speeds of about Mach 7. The propulsion system development and ground test will be conducted as the Integrated System Test of an Airbreathing Rocket (ISTAR) program. The vehicle under consideration for the flight test is a derivative of the current $X-43$ vehicle which is commonly known as Hyper- $X$. NASA participation in the program includes the Dryden Flight Test Center, Glenn Research Center, Langley Research Center and Marshall Space Flight Center. Industry representation includes Boeing for vehicle activities and Boeing's Rocketdyne Propulsion \& Power, Gencorp's Aerojet and United Technologies' Pratt \& Whitney companies. The propulsion companies have elected to combine their resources and to team for this program. The contractor team has been designated the Rocket Based Combined Cycle Consortium $\left(\mathrm{RBC}^{3}\right)$. As each of the three propulsion companies had unique approaches to RBCC propulsion systems, it was necessary to choose a single concept to adopt as the $\mathrm{RBC}^{3}$ propulsion system concept. The team propulsion system concept selected would then serve as the point of departure for design and development activities. A Flowpath Selection Team was established in June 2000 to accomplish the flowpath selection and consisted of two members from each propulsion company, two members from the vehicle contractor and a single member from each of the NASA centers participating in the program. A listing of the Flowpath Selection Team members is shown in Table 1. An effort was also initiated to bring a facilitator on board who could moderate the flowpath selection process. The RBCC concepts offered by the three propulsion companies are shown in Figure 1.

\section{Flowpath Selection Process Definition}

\footnotetext{
"Engineering Manager, Hypersonic Programs, Pratt \& Whitney

"Copyright $\odot 2001$ by the American Institute of Aeronautics and Astronautics, Inc. All rights reserved"
} 
The first meeting of the Flowpath Selection team consisted of the propulsion company members only and was held in early June 2000 for the purpose of discussing approaches to the flowpath selection process. During the two days of meetings, several products were generated. The team objectives and charter established were to define a selection process (including criteria, weighting and scoring procedures), provide an estimate for required resources and schedule for flowpath selection, get customer/program office buy-in of the flowpath selection approach, implement the selection process, make a flowpath selection, report the results and establish a recommended technical program plan. Norms for conducting business and roles/responsibilities of the vehicle contractor and NASA representatives were established. A top level selection process was developed during the meetings. To begin with, each company's hydrocarbon RBCC concept would be discussed and possibly evaluated using a team assessment tool. If one company's concept were clearly better than the other two concepts, then if would be selected for refinement through incorporation of technologies available from the other team members. If further discussion of the concepts originally presented was required, it was envisioned that the individual concepts would be modified by incorporation of technologies available from the other team members and these modified concepts would be evaluated for the preferred concept. This selection process is shown in Figure 2.

Having established the proposed team products, the remainder of the meeting was spent discussing the mechanics of evaluating the propulsion concepts. A strawman selection process based upon the Kemptner/Trago method for decision/selection processes was put before the team. This selection process would define the selection criteria by listing the program objectives, organize the criteria hierarchy by assigning weighting factors to each top level objective, subdivide each top level objective into elements, establish a technical description for each candidate flowpath, define the candidate flowpaths with supporting data and then score each of the candidate flowpaths with the "winner" having the highest total score. No decision was made regarding the proposed process mechanics at this time as the team members desired more time to consider it. However, it was decided to make an attempt to identify the flowpath selection categories and criteria that might be used. The criteria and their respective categories that were subsequently generated are shown in Table 2.

As this first series of meetings drew to a close, it became clear that there were several issues facing the team. First, the system requirements were not well understood. That is, is this a Mach 7 flight demonstration of RBCC technologies or a demonstration of a RBCC operational system? Was the $X-43 B$ vehicle a given or should the application of the RBCC propulsion concepts to other vehicle types be considered? Were selection criteria and rank ordering a given (there were some discussions during the meeting that a tops-down guidance had been provided)? Secondly, there was not a clear understanding of the proposed process that we would use. And finally, the team was having difficulty separating criteria from metrics, i.e. the measure you would use to score a criteria.

The next series of Flowpath Selection Team meetings was held following the ISTAR Conceptual Design Study Interim Review in late June 2000. The primary purpose in this series of meetings was to bring the NASA and airframer team members on board with accomplishments from the previous meetings and to acquaint everyone with the process proposed for use by the facilitator that was to be brought on board. The facilitator was not available for this series of meetings but the proposed structured decision making process was briefed to the team. The process begins by establishing the decisions that need to be made. This is followed by building decision networks to capture the order and dependency of the team's decisions. Once the decision networks are complete, a weighted set of criteria is established to evaluate the decisions, alternatives are then identified and assigned rankings would be normalized. Finally, a risk evaluation would be conducted for the concepts to ensure that a high risk solution was not selected for minimal benefit over the next highest score alternative.

A set of overall program objectives, approach and requirements were generated for concurrence by NASA Marshall management. Subsequent approval resulted in the following: 
- Overall Program Objectives

- Demonstrate a RBCC engine system from Mach 0 to Scramjet mode

- Ensure mission success by minimizing system complexity and technical risk; minimizing cost and schedule risk

- Program Approach

- Select a RBCC engine systems based on flight demonstration compatibility

- Develop a RBCC ground test program for:

- test of a flight-like, propellant cooled, thermally and power balanced RBCC engine system;

- development of a ground based technology test bed to demonstrate RBCC component and subsystem across the flight range;

- integration with flight vehicle to ensure compatibility with a flight test

- Flight demonstration requirements

- Hydrocarbon propellant

- Air launch from a B-52

- Accelerate from subsonic to scramjet mode

- Descend and land

- Reusable (25 flights)

- Meet range safety requirements

- System must be single fault tolerant for flight safety

- Ground test program requirements

- Stay within program schedule and budget

- Ground test total engine system at Stennis Space Center in 2004

July $10-13.2000$ - Flowpath Selection Process Definition with Facilitator

Chris Gackstatter of Coldspring Consulting was brought on-board to facilitate the flowpath selection process. The Kemptner/Trago based structured decision making approach was briefed to the team. After lengthy discussion it was suggested that we approach the flowpath selection task from a slightly different perspective given that three flowpath concepts currently exist and that we would not be starting with a cleansheet design. The new approach was described as a proposal evaluation approach, i.e. we have three flowpath proposals before us, how do we evaluate them. Using this "proposal evaluation" approach, the following top level criteria were identified: cost risk, schedule risk, technical merit. Technical Merit was further broken down with subcritera for Design Substantiation, Manufacturability and Technical Plan. The decision network is shown in Figure 3.

For Technical Merit, lower level criteria were defined; design substantiation, manufacturability and technical plan. For all criteria, musts and wants were established. In some cases, a criteria could be both a must and a want. For example, relative to structural margin, a concept must meet minimum structural requirements but margin above that minimum is a want. Once the criteria were established, weightings were set for each. The weightings were assigned values between 0 and 10 and reflect the relative importance of that particular criteria with the other criteria within that same category. The criteria, must/wants and weightings are defined in Table 3.

Having completed identification of the appropriate selection criteria and weightings, a format was established for presenting data on each of the engine concepts.

$$
\text { July } 26-28.2000 \text { - Data Exchange }
$$

Each company presented their respective RBCC propulsion system concepts.

$$
\frac{\text { July } 31-\text { August 4,2000 and August } 21-24}{2000-\text { Flowpath Evaluations }}
$$

Discussions of each RBCC propulsion system concept were conducted relative to each of the agreed upon criteria. Previous attempts to discuss the various concepts would always tend to swing from topic to topic but the structured decision making approach utilized by the facilitator allowed for pointed, focused discussions about a particular topic before moving on to the next. The structured approach employed in the flowpath discussions permitted all participants to reach a common and thorough understanding of each concept. In some instances, additional information was requested beyond that presented during the data exchange. For each criteria, scores were assigned for each concept relative to the others under consideration. It is important to note that the individual scores given each concept were not 
as important as the discussion that was held in establishing the individual scores.

\section{August 29-September 1,2000 - Flowpath Evaluation and Selection}

Having completed discussion and relative ranking of the criteria for each concept, it was decided to establish a listing of the issues associated with each of the engine concepts. For each issue, alternatives were identified should the issue arise and risks associated with each alternative were established. Following a very thorough discussion of the issues related to each engine concept, the NASA and vehicle representatives were released from further deliberations on the flowpath selection and the propulsion company team members continued the flowpath selection process.

To determine where the remaining team members were in the flowpath selection process, the six engine contractor team members were then asked to each select a flowpath and state the reasons behind picking that particular flowpath. However, a flowpath concept other than the concept offered by their company had to be chosen. Once each team member had selected a concept and stated their reasons for selecting it, common selection themes were noted. The common reasons for selecting a particular flowpath were importance of existing test hardware with rockets, traceability to vision vehicle, hydrocarbon database, variable geometry, and size growth potential. The existence of current test hardware with rockets was considered extremely important from a cost and schedule point of view. Since one of the requirements was to have a hot fire test at Stennis by the end of FY2004, concepts for which hardware already existed were considered to have a substantial benefit over concepts which would not have hardware available for testing for at least 6 to 9 months after program go-ahead. A majority of the team members also felt that the selected concept should maximize traceability to the vision vehicle and not just be a concept that only worked for the demonstrator vehicle. The existence and depth of a hydrocarbon fuel database was considered to be a very important factor as opposed to analysis that predicted a concept would work on hydrocarbon fuel. The existence of variable geometry was considered beneficial in that adjustments for performance and operability unknowns could be more readily accommodated with variable geometry as opposed to a fixed geometry design. As for size growth potential, some concepts can more readily accept engine length increases over others.

Following discussion of the common selection reasons, discussions continued until such time that consensus on a single propulsion concept was achieved. The Aerojet engine concept was unanimously selected as the going forward baseline for the team engine concept. This concept is now referred to as the ISTAR Reference Propulsion System.

\section{ISTAR Reference Propulsion System}

A schematic of the ISTAR Reference Propulsion System is shown in Figure 4. The various elements of the engine are identified. Ten individual flowpaths, each separated by a strut, comprise the complete propulsion system and are integrated into a single engine system using common turbopumps, propellant feed lines, cooling systems and controls. The overall propulsion system is shown in Figure 5.

There are three primary modes of operation for this propulsion system. The air-augmented rocket (AAR) mode provides acceleration from air-launch thru transonic and up to the point in the flight envelope where normal ramjet operation can be achieved. Transition to ramjet operation occurs about Mach 3 and fuel is injected at the rear of the struts in each flowpath. Acceleration continues until the Mach $6-7$ range when the fuel has been transitioned to the forward section of the strut and scramjet operation has been achieved. The various modes of operation are illustrated in Figure 6.

Selected components and the integrated flowpath of the ISTAR Reference Propulsion System have previously been demonstrated using hydrogen fuel as part of the NASA Marshall Advanced Reusable Technology program. Figure 7 shows the inlet model used in testing at the NASA Glenn Research Center 1' $x$ 1' Supersonic Wind Tunnel. Operability and performance data were collected up to simulated Mach 8 flight conditions. Additional inlet air capture tests were conducted up to simulated Mach 4 conditions in a heatsink freejet flowpath model shown in Figure 8. 
Performance and operability tests of the flowpath model were conducted at GASL at simulated flight conditions up to Mach 8 . All three modes of operation were demonstrated, i.e. air augmented rocket mode, ramjet mode and scramjet mode.

\section{ISTAR Program}

The goal of the ISTAR Engine Project is to enable a revolutionary step forward in Earth to Orbit vehicle. During the execution of the conceptual design studies, the three companies agreed to team and develop a single RBCC propulsion system concept. Upon selection of the ISTAR Reference Propulsion System by the Flowpath Selection Team in mid-2000, all activities were then focused on definitizing the selected propulsion system. Selected activities to work identified issues with the Reference Propulsion System were initiated in January 2001. Phase 1 of the ISTAR program is scheduled to begin in June 2001 and lead to a Systems Requirement Review in mid-2002. Detailed design of the ISTAR propulsion system will be initiated in Phase 2 leading to the ground test of the engine system in late 2005. The next step is to flight test the engine system. At this writing, no flight test demonstrator program exists. Funding to begin the flight program is being worked into the budget submittal for FY03. The ISTAR program schedule is depicted in Figure 9. The anticipated flight test demonstrator program is also shown.

Acknowledgements propulsion through the design, fabrication, and test of an airframe-integrated, combined cycle engine system. The engine is also envisioned to provide a technology test bed where RBCC engine technologies, and other technologies, can be demonstrated in both a ground and a test flight environment. Aerojet, Pratt \& Whitney and Rocketdyne were given study contracts in early 2000 to conceptualize RBCC propulsion systems for integration with a derivative of the Hyper- $X$

The author would like to recognize the significant contributions of the entire ISTAR Flowpath Selection Team.

- Stephen Beckel, Pratt \& Whitney

- Thomas Bogar, Boeing

- Kevin Bowcutt, Boeing

- Mel Bulman, Aerojet

- Stephen Corda, NASA Dryden Flight Test Center

- Mike Fazah, NASA Marshall Space Flight Center

- Allan Goldman, Rocketdyne

- Don Messitt, Aerojet

- George O'Connor, Rocketdyne

- Scott Thomas, NASA Glenn Research Center

- Randy Voland, NASA Langley Research Center

\section{References}

1. Siebenhaar, Bulman, Johnson and Fazah, "Demonstrating the Performance Benefits of the Strutjet RBCC for Space Launch Architectures", ISABE IS-232, September 1999, Florence, Italy. 


\begin{tabular}{|c|c|}
\hline AFFILIATION & MEMBER \\
\hline Aerojet & $\begin{array}{c}\text { Mel Bulman } \\
\text { Don Messitt }\end{array}$ \\
\hline Boeing & $\begin{array}{c}\text { Tom Bogar } \\
\text { Kevin Bowcutt }\end{array}$ \\
\hline NASA Dryden Flight Test Center & Stephen Corda \\
\hline NASA Glenn Research Center & Scott Thomas \\
\hline NASA Langley Research Center & Randy Voland \\
\hline NASA Marshall Space Flight Center & Mike Fazah \\
\hline Pratt \& Whitney & $\begin{array}{c}\text { Steve Beckel } \\
\text { Bob Faulkner }\end{array}$ \\
\hline Rocketdyne & $\begin{array}{c}\text { Allen Goldman } \\
\text { George O'Connor }\end{array}$ \\
\hline
\end{tabular}

Table 1: ISTAR Flowpath Selection Team Members

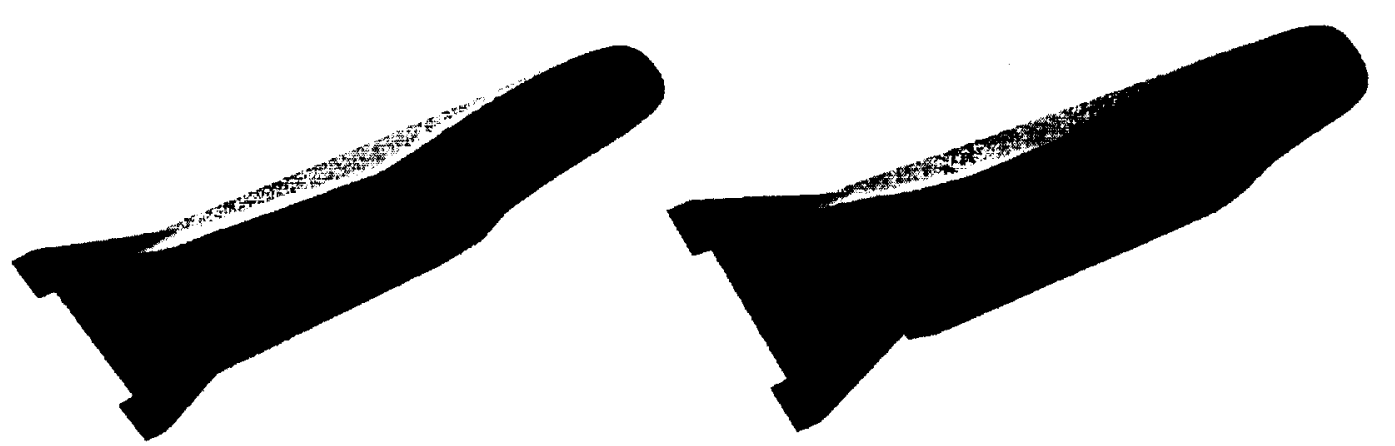

Aerojet Engine Concept

P\&W Engine Concept

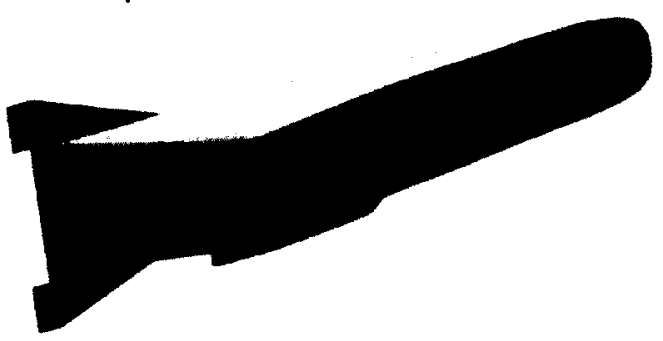

Rocketdyne Engine Concept

Figure 1: Rocket Based Combined Cycle Concepts 


\begin{tabular}{|c|c|}
\hline Criteria & Category \\
\hline 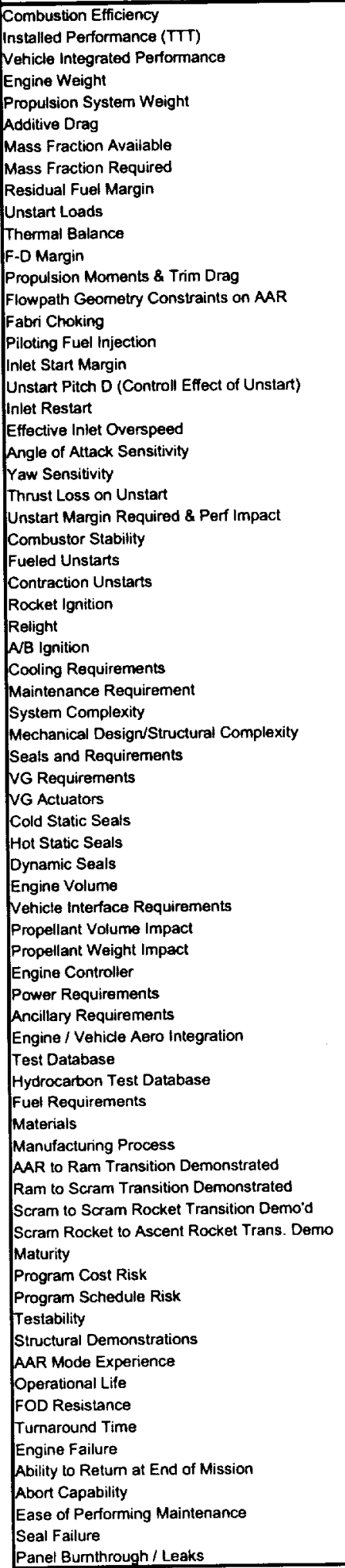 & 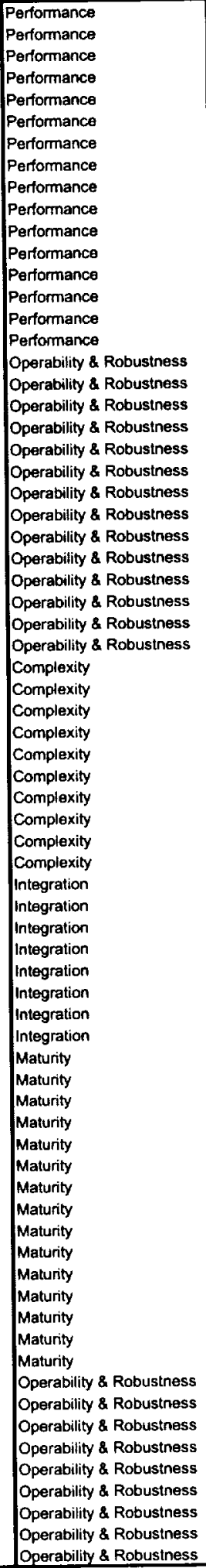 \\
\hline
\end{tabular}

Table 2: Early Candidate Flowpath Selection Criteria 


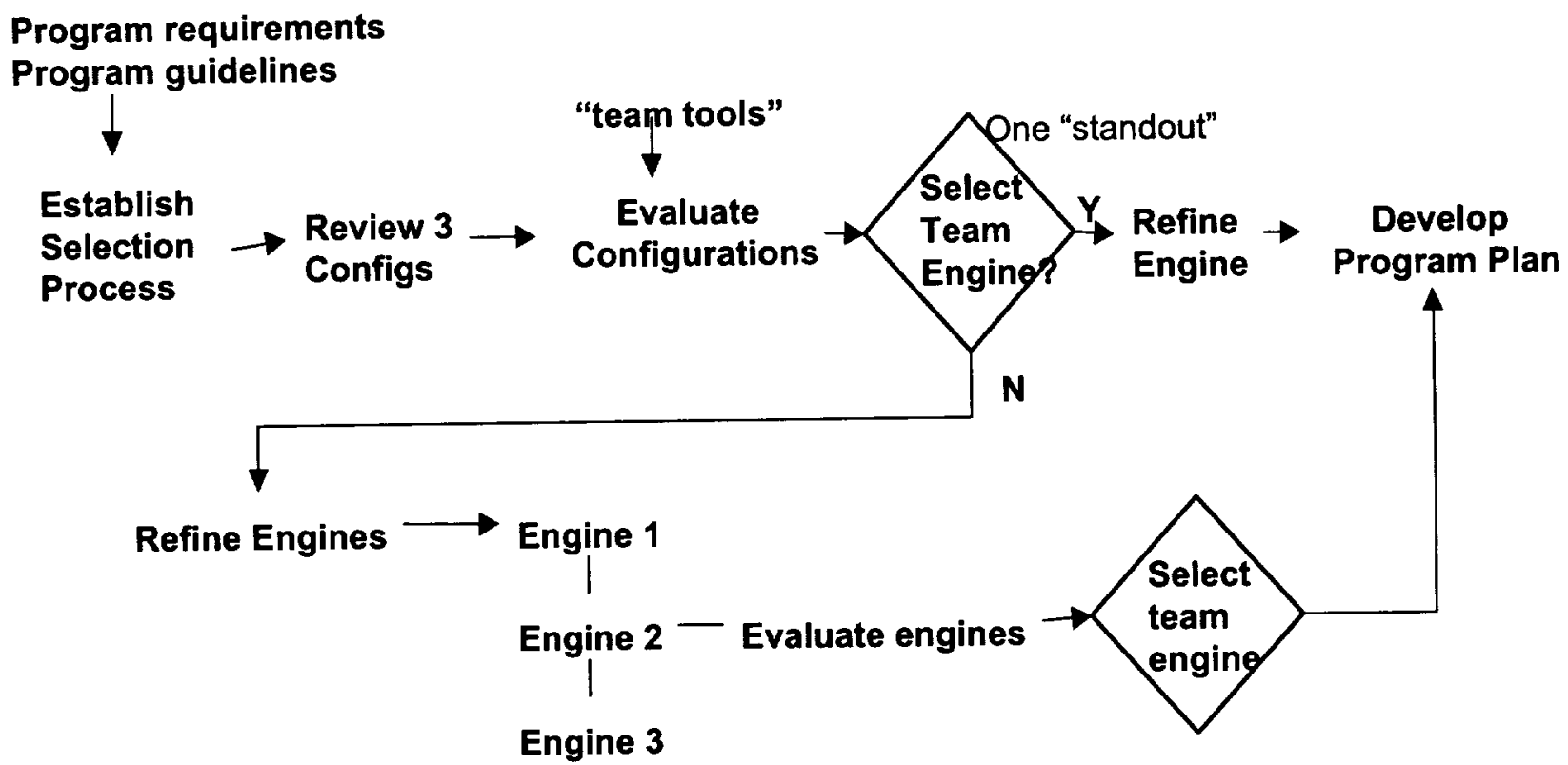

Figure 2: Flowpath Selection Process Flowchart

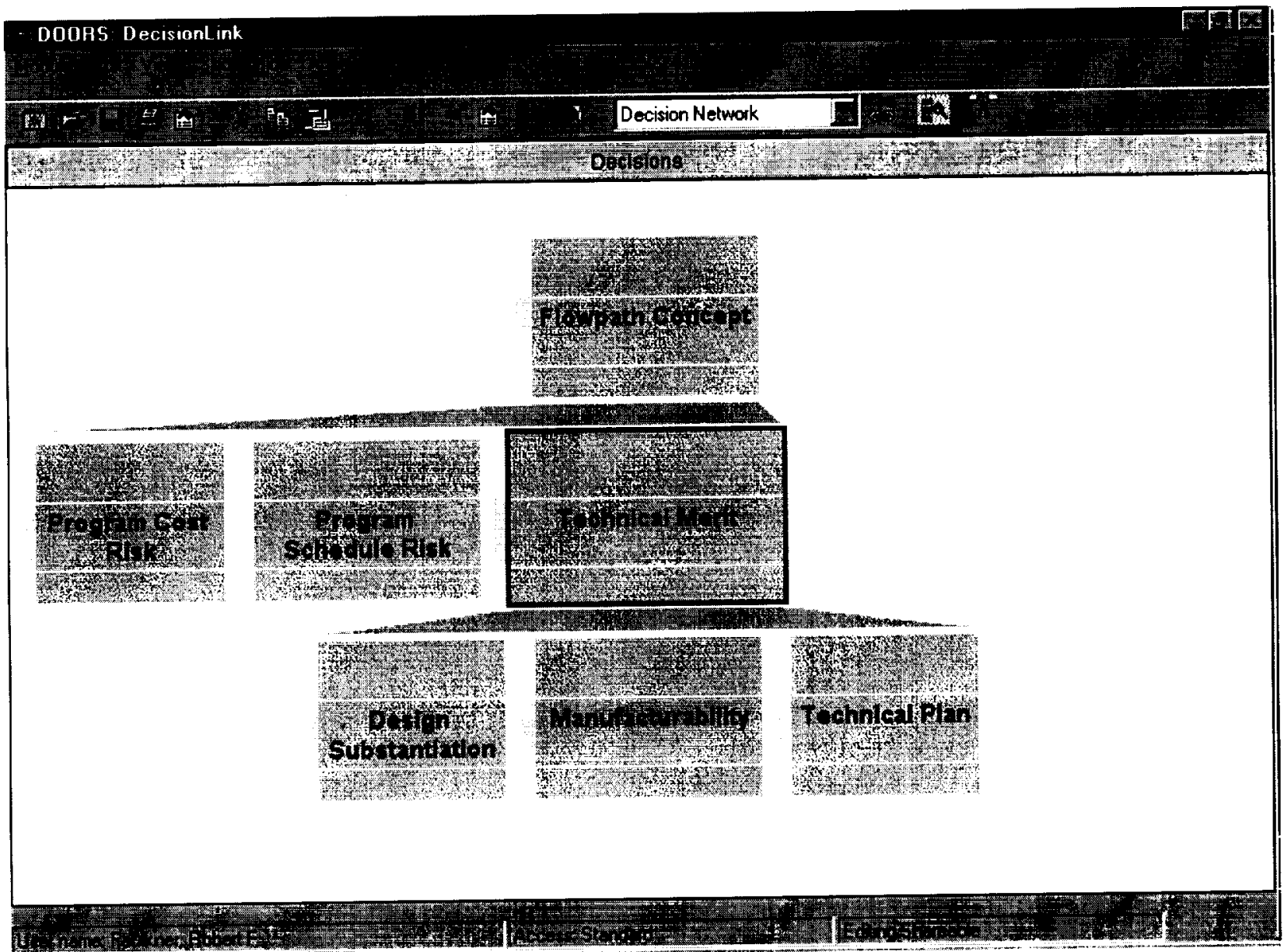


Figure 3: Flowpath Selection Decision Network

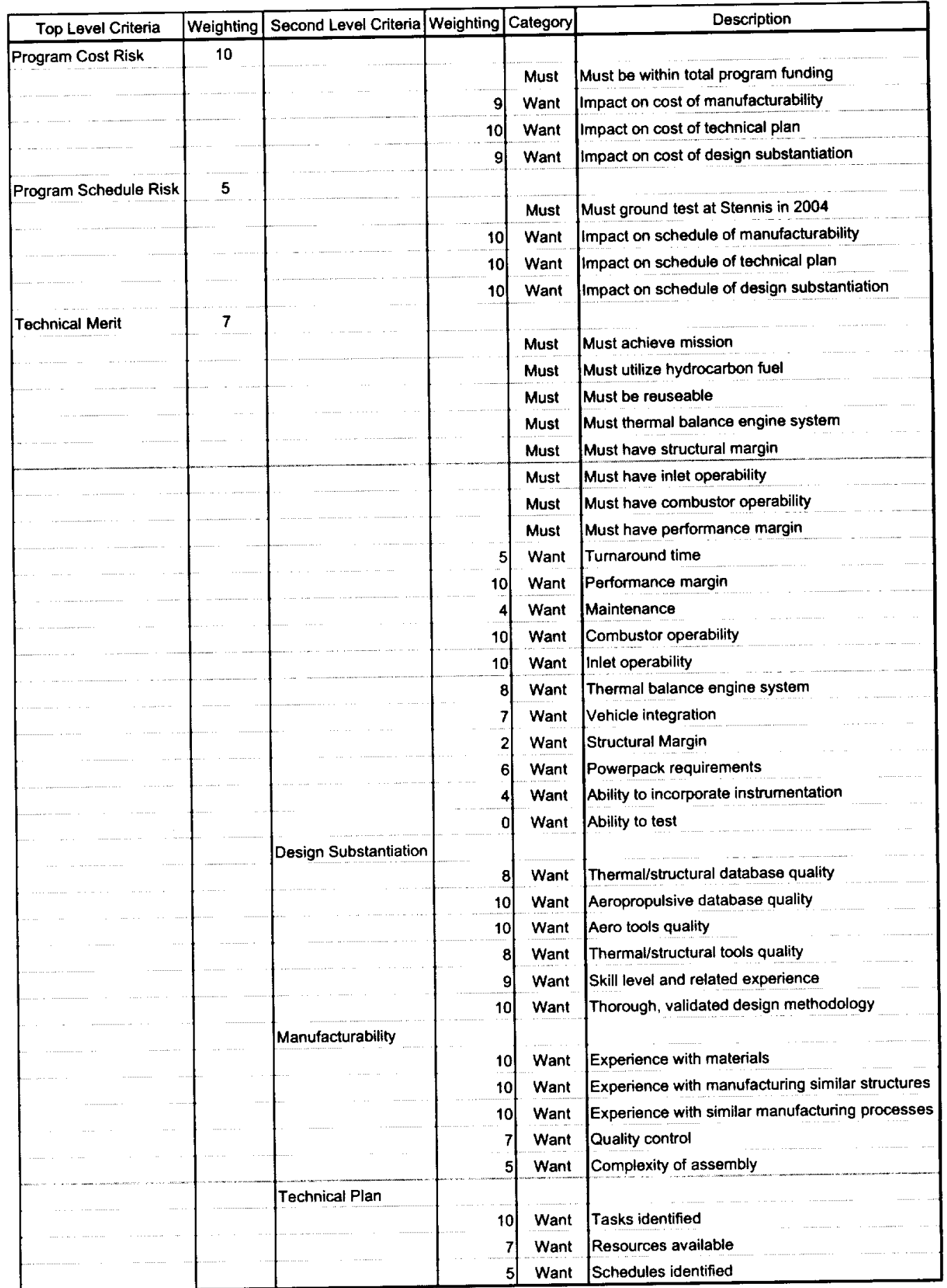

Table 3 Flowpath Selection Criteria, Must/Wants and Weightings 


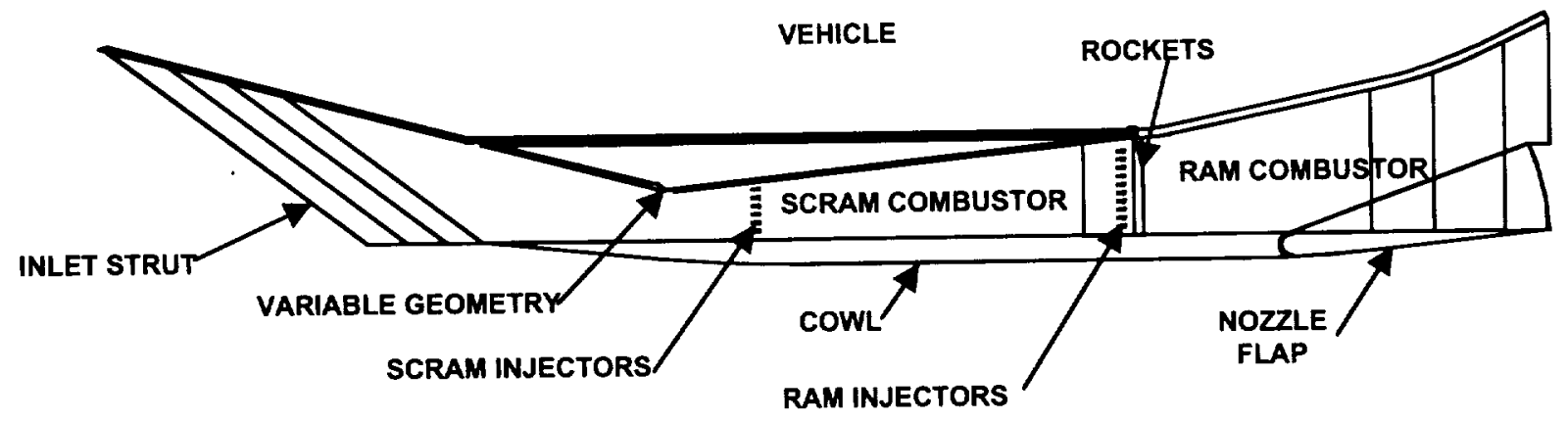

Figure 4: ISTAR Reference Propulsion System Schematic

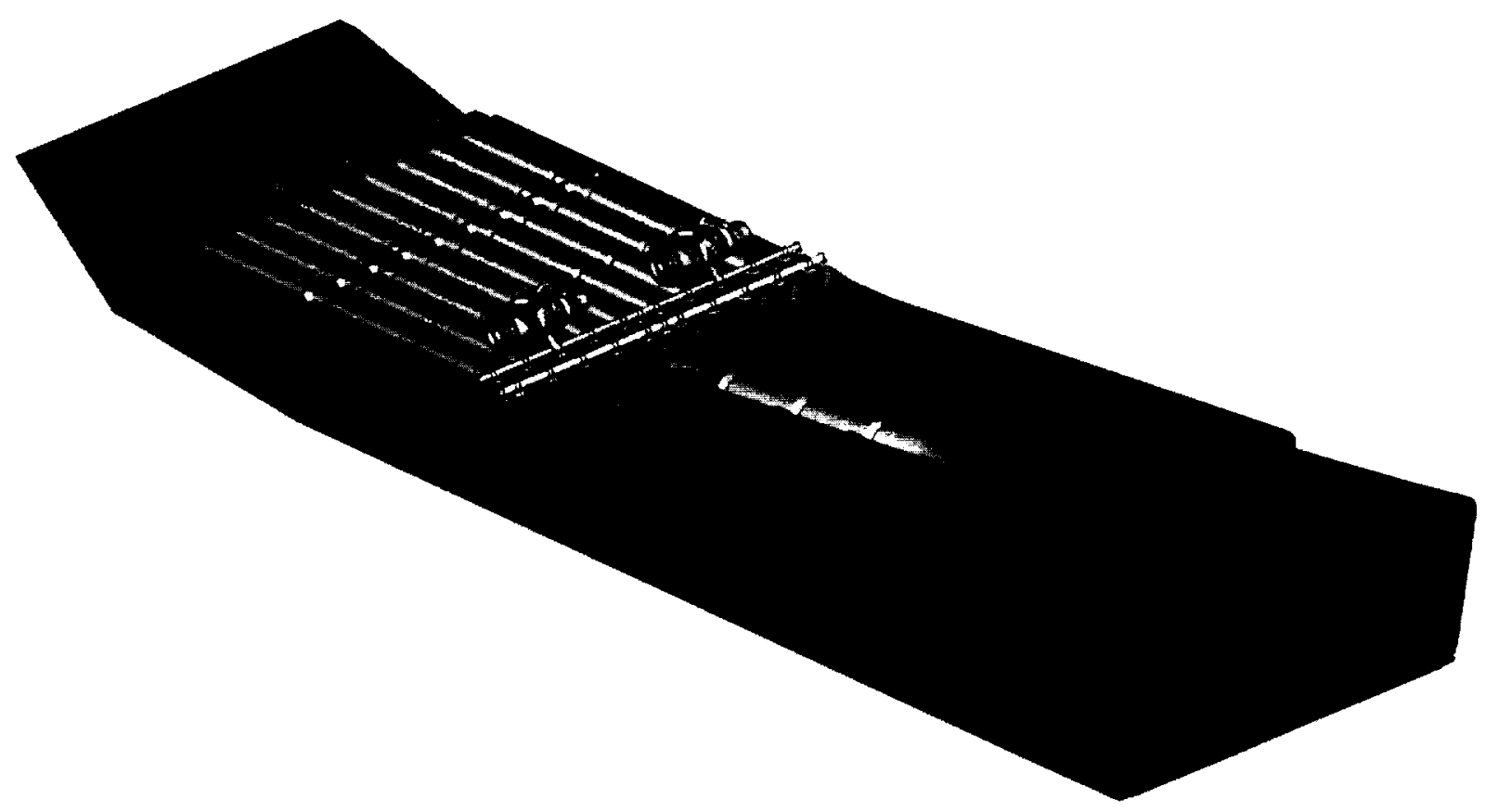

Figure 5: Overall ISTAR Propulsion System 
AAR $(M<3.0)$

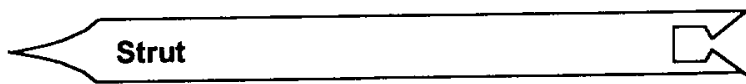

\section{Fuel Rich Rog: :}

Ramjet

$(3<M<6)$

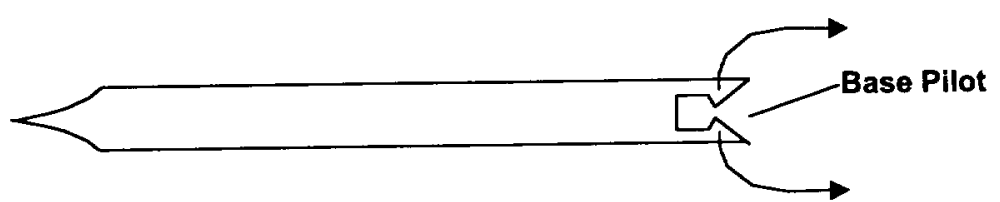

Aft Normal Injector

Scramjet $(6<M<7)$

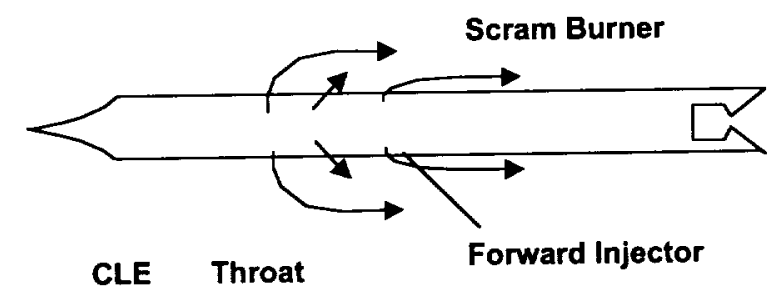

Figure 6: RBCC Modes of Operation

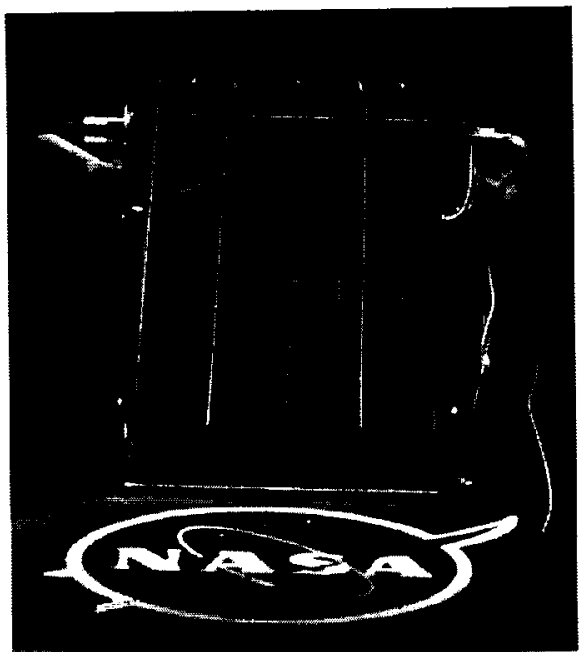

Figure 7: ART Inlet Model Tested at NASA Glenn Research Center 


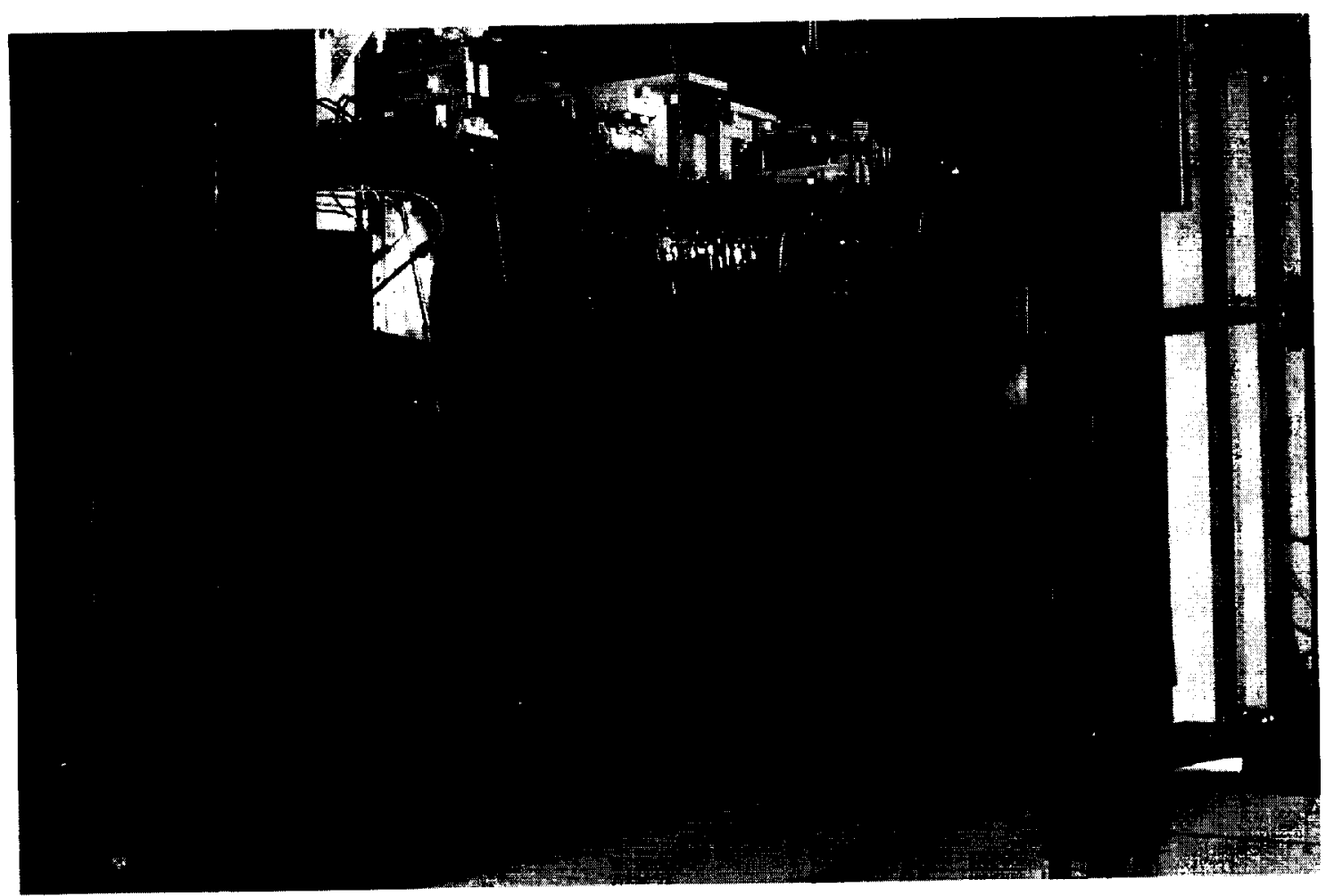

Figure 8: ART Freejet Engine

00

01

02

03

04

05

06

07

08

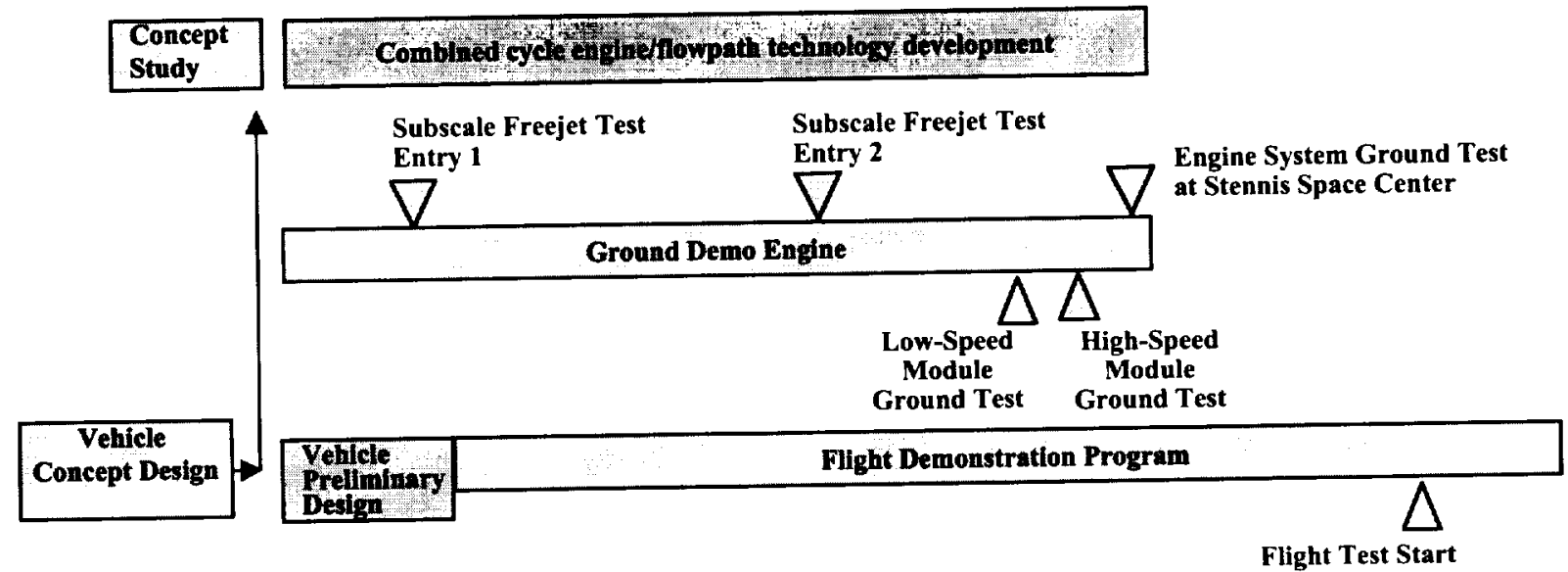

Figure 9: ISTAR Program Plan 